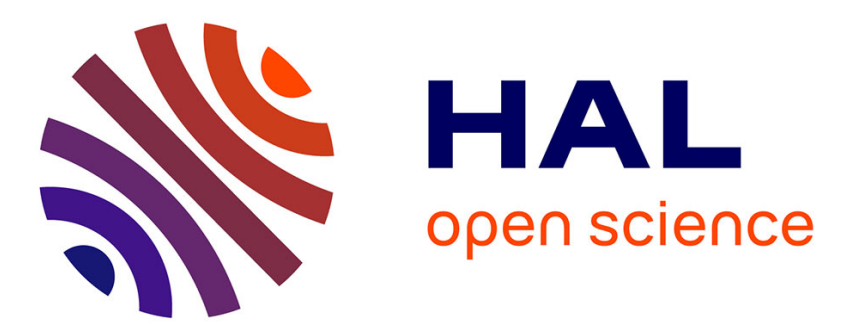

\title{
A mathematical explanation via "intelligent" PID controllers of the strange ubiquity of PIDs
}

Brigitte d'Andréa-Novel, Michel Fliess, Cédric Join, Hugues Mounier, Bruno Steux

\section{- To cite this version:}

Brigitte d'Andréa-Novel, Michel Fliess, Cédric Join, Hugues Mounier, Bruno Steux. A mathematical explanation via "intelligent" PID controllers of the strange ubiquity of PIDs. 18th Mediterranean Conference on Control and Automation, MED'10, IEEE, Jun 2010, Marrakech, Morocco. pp.CDROM, 10.1109/med.2010.5547700 . inria-00480293v2

\section{HAL Id: inria-00480293 https://hal.inria.fr/inria-00480293v2}

Submitted on 29 Jun 2010

HAL is a multi-disciplinary open access archive for the deposit and dissemination of scientific research documents, whether they are published or not. The documents may come from teaching and research institutions in France or abroad, or from public or private research centers.
L'archive ouverte pluridisciplinaire HAL, est destinée au dépôt et à la diffusion de documents scientifiques de niveau recherche, publiés ou non, émanant des établissements d'enseignement et de recherche français ou étrangers, des laboratoires publics ou privés. 


\title{
A mathematical explanation via "intelligent" PID controllers of the strange ubiquity of PIDs
}

\author{
Brigitte d'Andréa-Novel, Michel Fliess, Cédric Join, Hugues Mounier, Bruno SteuX
}

\begin{abstract}
The ubiquity of PID controllers in the industry has remained mysterious until now. We provide here a mathematical explanation of this strange phenomenon by comparing their sampling with the the one of "intelligent" PID controllers, which were recently introduced. Some computer simulations nevertheless confirm the superiority of the new intelligent feedback design.
\end{abstract}

Keywords- PID, model-free control, intelligent PID, sampling.

\section{INTRODUCTION}

PI and PID controllers (see, e.g., [2], [16]) are still by far the most popular feedback design in industry. To the best of our knowledge, there is no clear-cut explanation of their strange ubiquity for a wide range of systems. Remember that, from a purely mathematical standpoint, they are only fully justified until now for first and second order linear differential equations with constant coefficients! We solve here this long-standing and quite irritating open problem via the newly introduced intelligent PIDs ([6], [7]), which have already been utilized quite successfully in several concrete situations (see, e.g., [1], [4], [10], [11], [13], [14], [18]).

The proof relies on a crude time-sampling of both types of regulators. It shows that the gains in a classic PI or PID take into account, if they are properly tuned, the estimated "structural" part of the intelligent controllers. Thus the efficiency of these intelligent controllers with respect to arbitrary nonlinear plants ([6], [7]) is enough for fulfilling our purpose. Let us nevertheless emphasize that the classic tuning rules are quite intricate whereas their counterparts for intelligent controllers are obvious.

Remark 1.1: Only few references (see, e.g., [3], [12]) in the huge literature on PIDs exhibit some connections with our viewpoint.

Our paper is organized as follows. Section III is devoted to a brief review of model-free control and of the corresponding intelligent PID controllers. Section IIII, which establishes our

Brigitte d'AndRÉA-Novel is with Centre de Robotique, MinesParisTech, 75272 Paris Cedex 06, France.

Brigitte. Dandrea-Novel@mines-paristech.fr

Michel FLIESS is with INRIA-ALIEN \& LIX (CNRS, UMR 7161), École polytechnique, 91128 Palaiseau, France.

Michel.Fliess@polytechnique.edu

Cédric JOIN is with INRIA-ALIEN \& CRAN (CNRS, UMR 7039), Nancy-Université, BP 239, 54506 Vandœuvre-lès-Nancy, France.

cedric.join@cran.uhp-nancy. fr

Hugues MounIER is with L2S (CNRS, UMR 8506), Supélec \& Université Paris-Sud, 3 rue Joliot-Curie, 91192 Gif-sur-Yvette, France.

Hugues. Mounierdis. supelec.fr

Bruno SteUX is with Centre de Robotique, Mines-ParisTech, 75272 Paris Cedex 06, France.

Bruno. Steux@mines-paristech.fr results by comparing the sampling of classical and intelligent controllers, gives a table for the connections between classic and intelligent gains. The computer simulations in Section IV confirms the superiority of the intelligent controllers (see, also, [6], [7] for other examples). Some concluding remarks are given in Section $\mathrm{V}$.

\section{MODEL-FreE CONTROL}

The input-output behavior of the system, which for simplicity's sake is assumed to be monovariable, is "approximatively" governed within its operating range by an unknown finite-dimensional ordinary differential equation, which is not necessarily linear,

$$
E\left(y, \dot{y}, \ldots, y^{(a)}, u, \dot{u}, \ldots, u^{(b)}\right)=0
$$

Replace Equation (11) by the following "phenomenological" model, which is only valid during a very short time interval,

$$
y^{(\nu)}=F+\alpha u
$$

The derivation order $\nu$, which is in general equal to 1 or 2 , and the constant parameter $\alpha$ are chosen by the practitioner. It implies that $\nu$ is not necessarily equal to the derivation order $a$ of $y$ in Equation (11). The numerical value of $F$ at any time instant is deduced from those of $u$ and $y^{(\nu)}$, thanks to our quite efficient numerical differentiators, which are moreover real-time. 7 The desired behavior is obtained by implementing, if, for instance, $\nu=2$, the intelligent PID controller (i-PID)

$$
u=\frac{1}{\alpha}\left(-F+\ddot{y}^{*}+K_{P} e+K_{I} \int e+K_{D} \dot{e}\right)
$$

where

- $y^{*}$ is the output reference trajectory, which is determined e.g. via the rules of flatness-based control;

- $e=y-y^{*}$ is the tracking error;

- $K_{P}, K_{I}, K_{D}$ are the usual tuning gains.

Let us consider the following special cases:

- If again $\nu=2$, we may use an intelligent $P D$ controller $(i-P D)$

$$
u=\frac{1}{\alpha}\left(-F+\ddot{y}^{*}+K_{P} e+K_{D} \dot{e}\right)
$$

- If $\nu=1$, we can restrict ourselves to

${ }^{1}$ See [6], [7] for more details.

${ }^{2}$ See [8], [15] for details, and also [9]. 
- an intelligent PI controller (i-PI)

$$
u=\frac{1}{\alpha}\left(-F+\dot{y}^{*}+K_{P} e+K_{I} \int e\right)
$$

- or even to an intelligent $P$ controller $(i-P)$

$$
u=\frac{1}{\alpha}\left(-F+\dot{y}^{*}+K_{P} e\right)
$$

Remark 2.1: If $\nu=2$ (resp. 1), plugging Equations (3) or (4) (resp. (5) or (6)) in Equation (2) yields the control of a pure double (resp. simple) integrator. This is why tuning the gains of our intelligent controllers is quite straightforward.

Remark 2.2: It should be emphasized, if $\nu=2$ (resp. 1), that Equation (4) (resp. (6)) is mathematically sufficient for ensuring stability around the reference trajectory. The integral term $K_{I} \int e$ in Equation (3) (resp. (5)) nevertheless adds some well known robustness properties.

\section{CONNECTIONS BETWEEN CLASSIC AND INTELLIGENT CONTROLLERS}

\section{A. PI and $i-P$}

1) A crude sampling of PIs: Consider the classic continuous-time PI controller

$$
u(t)=k_{p} e(t)+k_{i} \int e(\tau) d \tau
$$

A crude sampling of the integral $\int e(\tau) d \tau$ through a Riemann sum $I(t)$ leads to

$$
\int e(\tau) d \tau \simeq I(t)=I(t-h)+h e(t)
$$

where $h$ is the sampling interval. The corresponding discrete form of Equation (7) reads:

$$
u(t)=k_{p} e(t)+k_{i} I(t)=k_{p} e(t)+k_{i} I(t-h)+k_{i} h e(t)
$$

Combining the above equation with

$$
u(t-h)=k_{p} e(t-h)+k_{i} I(t-h)
$$

yields

$$
u(t)=u(t-h)+k_{p}(e(t)-e(t-h))+k_{i} h e(t)
$$

Remark 3.1: A trivial sampling of the "velocity form" of Equation (77)

$$
\dot{u}(t)=k_{p} \dot{e}(t)+k_{i} e(t)
$$

yields

$$
\frac{u(t)-u(t-h)}{h}=k_{p}\left(\frac{e(t)-e(t-h)}{h}\right)+k_{i} e(t)
$$

which is equivalent to Equation (8).
2) Sampling i-Ps: Utilize, if $\nu=1$ in Equation (2), the i-P (6), which may be rewritten as

$$
u(t)=\frac{\dot{y}^{*}(t)-F+K_{P} e(t)}{\alpha}
$$

Replace, according to the computer implementation in [6], [7], $F$ by $\dot{y}(t)-\alpha u(t-h)$ and therefore by

$$
\frac{y(t)-y(t-h)}{h}-\alpha u(t-h)
$$

It yields

$$
u(t)=u(t-h)-\frac{e(t)-e(t-h)}{h \alpha}+\frac{K_{P}}{\alpha} e(t)
$$

3) Comparison: FACT.- Equations (8) and (9) become identical if we set

$$
k_{p}=-\frac{1}{\alpha h}, \quad k_{i}=\frac{K_{P}}{\alpha h}
$$

Remark 3.2: It should be emphasized that the above property, defined by Equations (10), does not hold for continuoustime PIs and i-Ps. This equivalence is strictly related to time sampling, i.e., to computer implementation, as demonstrated by taking $h \rightarrow 0$ in Equations (10).

\section{B. PID and $i-P D$}

Extending the calculations of Section III-A is quite obvious. The velocity form of the PID

$$
u(t)=k_{p} e(t)+k_{i} \int e(\tau) d \tau+k_{d} \dot{e}
$$

reads $\dot{u}(t)=k_{p} \dot{e}(t)+k_{i} e(t)+k_{d} \ddot{e}(t)$. It yields the obvious sampling

$$
u(t)=u(t-h)+k_{p} h \dot{e}(t)+k_{i} h e(t)+k_{d} h \ddot{e}(t)
$$

If $\nu=2$ on the other hand, Equation (4) yields $u(t)=$ $\frac{1}{\alpha}\left(\ddot{y}^{*}(t)-F+K_{P} e(t)+K_{D} \dot{e}(t)\right)$. From the computer implementation $F=\ddot{y}(t)-\alpha u(t-h)$, we derive

$$
u(t)=u(t-h)-\frac{1}{\alpha} \ddot{e}(t)+\frac{K_{P}}{\alpha} e(t)+\frac{K_{D}}{\alpha} \dot{e}(t)
$$

FACT.- Equations (11) and (12) become identical if we set

$$
k_{p}=\frac{K_{D}}{\alpha h}, \quad k_{i}=\frac{K_{P}}{\alpha h}, \quad k_{d}=-\frac{1}{\alpha h}
$$

C. $i$-PI and $i-P I D$

Equation (12) becomes with the i-PID (3)

$$
u(t)=u(t-h)-\frac{1}{\alpha} \ddot{e}(t)+\frac{K_{P}}{\alpha} e(t)+\frac{K_{I}}{\alpha} \int e+\frac{K_{D}}{\alpha} \dot{e}(t)
$$

Introduce the $\mathrm{PII}^{2} \mathrm{D}$ controller

$$
u(t)=k_{p} e(t)+k_{i} \int e(\tau) d \tau+k_{i i} \iint e d \tau d \sigma+k_{d} \dot{e}(t)
$$

where a double integral appears. [ $^{\text {To }}$ its velocity form $\dot{u}(t)=$ $k_{p} \dot{e}(t)+k_{i} e+k_{i i} \int e d \tau+k_{d} \ddot{e}(t)$ corresponds the sampling $u(t)=u(t-h)+k_{p} h \dot{e}(t)+k_{i} h e+k_{i i} h \int e d \tau+k_{d} h \ddot{e}(t)$

\footnotetext{
${ }^{3}$ Such double integrals do not seem to be common in control engineering.
} 
which is identical to Equation (14) if one sets

$$
k_{p}=\frac{K_{D}}{\alpha h}, \quad k_{i}=\frac{K_{P}}{\alpha h}, \quad k_{i i}=\frac{K_{I}}{\alpha h}, \quad k_{d}=-\frac{1}{\alpha h}
$$

The connection between iPIs and $\mathrm{PII}^{2} \mathrm{~s}$ follows at once.

\section{Table of correspondence}

The previous calculations yield the following correspondence table between the gains of our various controllers:

Remark 3.3: Due to the form of Equation (2), it should be noticed that the tuning gains of the classic regulators ought to be negative.

\section{E. The explanation}

The previous calculations and Table 1 explain why sampled classic PI and PID controllers take into account, if their gains are properly tuned, the structural term $-F / \alpha$, which contains all the structural information of the unknown nonlinear systems, in Equations (3), (4), (5), (6). The superiority of intelligent controllers, which was already noted in [6], [7], is however confirmed:

1) Tuning the gains of intelligent controllers is straightforward whereas it is complex and painful for classic PIDs in spite of all the numerous existing rules in the literature (see, e.g., [2], [16]).

2) Contrarily to intelligent controllers, a correctly tuned classic PI or PID controller is unable to take into account heat effects, ageing processes, characteristic dispersions due to mass production, ....

3) Fault tolerant control is much better handled by intelligent controllers than by classic ones.

\section{Classic Versus intelligent CONTROLlers}

For the nonlinear system

$$
\dot{y}+y^{3}=2 u
$$

we deduce a classic PI controller thanks to a method due to Broïda and Dindeleux [5] which improves the well-known Ziegler-Nichols rules (see, e.g., [2], [16]). Note however that the open loop response of System $(16)$, with $y(0)=0$, is somehow difficult to exploit as shown by Figure 11. It yields

- a delay system

$$
\frac{k e^{-\tau s}}{1+T s}
$$

where $k=1.160, T=0.401, \tau=0.044$;

- a PI where $k_{p}=6.350, k_{i}=15.817$.

Figures 2 and 3 , which depict the simulation results for the above PI and an i-PI, do not show any significant difference. Remember however that the i-PI, where $\alpha=1, K_{P}=6$, $K_{I}=9$, does not necessitate any cumbersome identification procedure.

Without any new calibration of the PI for another operating range Figure $\$$ shows a deterioration of the performances, whereas the performances of the i-PI, which are depicted in Figure 5, remain good.

\footnotetext{
${ }^{4}$ See [6], [7] for other examples.
}

Introduce now a fault accommodation via a control power loss $u_{\text {Pert }}=0.996^{t / h} \times u, t>4$, where the sampling time $h=0.01 s$. The i-PI behaves then much better (Figure 77) than the PI (Figure 6). Note nevertheless a small deviation of the i-PI controller when the power loss becomes quite important (Figure 7-(b)).

\section{CONCLUSION}

The above numerical simulations as well as many existing experimentations (see [6], [7], and [1], [4], [10], [11], [13], [14], [18]) demonstrate that intelligent PID controllers yield better performances than classic ones. This is achieved moreover thanks to a quite straightforward and natural gain tuning, which contrasts with the numerous complex rules for classic PIDs. Those considerations as well as the results of this communication imply therefore

- that classic PIDs might become obsolete,

- a change of paradigm for control engineering, and for its teaching (see, e.g., [6], [7], and [17]).

\section{REFERENCES}

[1] B. d'Andréa-Novel, C. Boussard, M. Fliess, O. El Hamzaoui, H. Mounier, B. Steux, Commande sans modèle de vitesse longitudinale d'un véhicule électrique, $\sigma^{e}$ Conf. Internat. Francoph. Automatique, Nancy, 2010 (online http://hal.inria.fr/inria-00463865/en/).

[2] K.J. Àström, T. Hägglund, Advanced PID Control, Instrument Soc. Amer., 2006

[3] P.H. Chang, J.H. Jung, A systematic method for gain selection of robust PID control for nonlinear plants of second-order controller canonical form, IEEE Trans. Control Systems Technology, vol. 17, pp. 473-483, 2009.

[4] S. Choi, B. d'Andréa-Novel, M. Fliess, H. Mounier, Model-free control of automotive engine and brake for stop-and-go scenario, $10^{\text {th }}$ IEEE Conf. Europ. Control Conf., Budapest, 2009 (online http://hal.inria.fr/inria-00419445/en/).

[5] D. Dindeleux, Technique de la regulation industrielle, Eyrolles, 1981.

[6] M. Fliess, C. Join, Commande sans modèle et commande à modèle restreint, $e-S T A$, vol. 5 ( $\mathrm{n}^{\circ} 4$ ), pp. 1-23, 2008 (online http://hal.inria.fr/inria-00288107/en/).

[7] M. Fliess, C. Join, Model-free control and intelligent PID controllers: towards a possible trivialization of nonlinear control?, $15^{\text {th }}$ IFAC Symp. System Identif., Saint-Malo, 2009 (online http://hal.inria.fr/inria-00372325/en/).

[8] M. Fliess, C. Join, H. Sira-Ramírez, Non-linear estimation is easy, Int. J. Model. Identif. Control, vol. 4, pp. 12-27, 2008 (online http://hal.inria.fr/inria-00158855/en/).

[9] García Collado F.A., d'Andréa-Novel B., Fliess M., Mounier H., Analyse fréquentielle des dérivateurs algébriques, XXII Coll. GRETSI, Dijon, 2009

(online http://hal.inria.fr/inria-00394972/en/).

[10] P.-A. Gédouin, C. Join, E. Delaleau, J.-M. Bourgeot, S. Arbab-Chirani, S. Calloch, Model-free control of shape memory alloys antagonistic actuators, $17^{\text {th }}$ IFAC World Congress, Seoul, 2008 (online http://hal.inria.fr/inria-00261891/en/).

[11] P.-A. Gédouin, C. Join, E. Delaleau, J.-M. Bourgeot, S. Arbab-Chirani, S. Calloch, A new control strategy for shape memory alloys actuators, $8^{\text {th }}$ Europ. Symp. Martensitic Transformations, Prague, 2009 (online http://hal.inria.fr/inria-00424933/en/).

[12] J. Han, From PID to active disturbance rejection control, IEEE Trans. Ind. Elec., vol. 56, pp. 900-906, 2009.

[13] C. Join, J. Masse, M. Fliess, Étude préliminaire d'une commande sans modèle pour papillon de moteur, $J$. europ. syst. automat., vol. 42, pp. 337-354, 2008 (online http://hal.inria.fr/inria-00187327/en/).

[14] C. Join, G. Robert, M. Fliess, Vers une commande sans modèle pour aménagements hydroélectriques en cascade, $6^{e}$ Conf. Internat. Francoph. Automat., Nancy, 2010 (online http://hal.inria.fr/inria-00460912/en/). 


\begin{tabular}{|c|c|c|c|c|c|}
\hline & & i-P & i-PD & i-PI & i-PID \\
\hline PI & $\begin{array}{l}k_{p} \\
k_{i}\end{array}$ & $\begin{array}{l}-1 / \alpha h \\
K_{P} / \alpha h\end{array}$ & & & \\
\hline PID & $\begin{array}{l}k_{p} \\
k_{i} \\
k_{d}\end{array}$ & & $\begin{array}{l}K_{D} / \alpha h \\
K_{P} / \alpha h \\
-1 / \alpha h\end{array}$ & & \\
\hline $\mathrm{PII}^{2}$ & $\begin{array}{l}k_{p} \\
k_{i} \\
k_{i i}\end{array}$ & & & $\begin{array}{l}-1 / \alpha h \\
K_{P} / \alpha h \\
K_{I} / \alpha h\end{array}$ & \\
\hline $\mathrm{PII}^{2} \mathrm{D}$ & $\begin{array}{l}k_{p} \\
k_{i} \\
k_{i i} \\
k_{d}\end{array}$ & & & & $\begin{array}{l}K_{D} / \alpha h \\
K_{P} / \alpha h \\
K_{I} / \alpha h \\
-1 / \alpha h\end{array}$ \\
\hline
\end{tabular}

TABLE I: Correspondence between the gains of sampled classic and intelligent controllers.

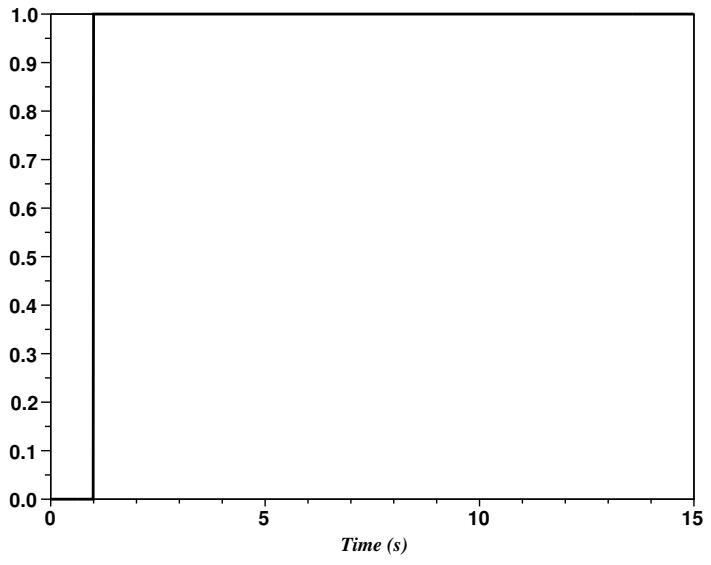

(a) Input

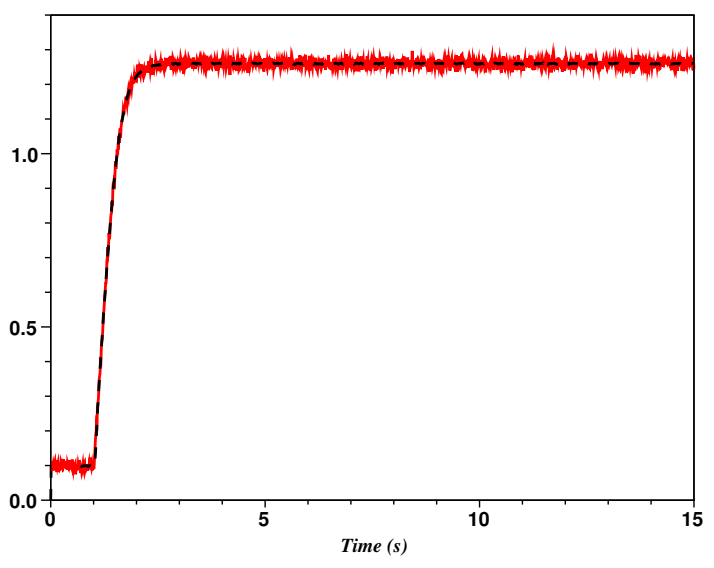

(b) Output (-) and denoised output (- -)

Fig. 1: Open loop case

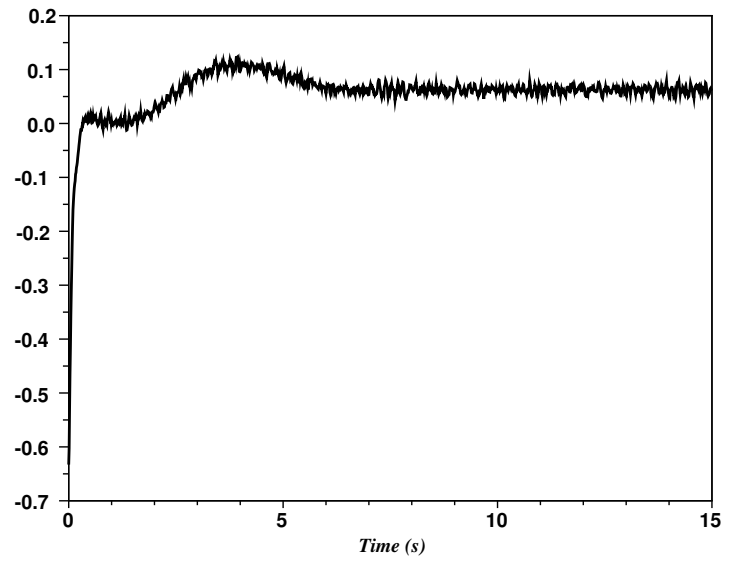

(a) Input

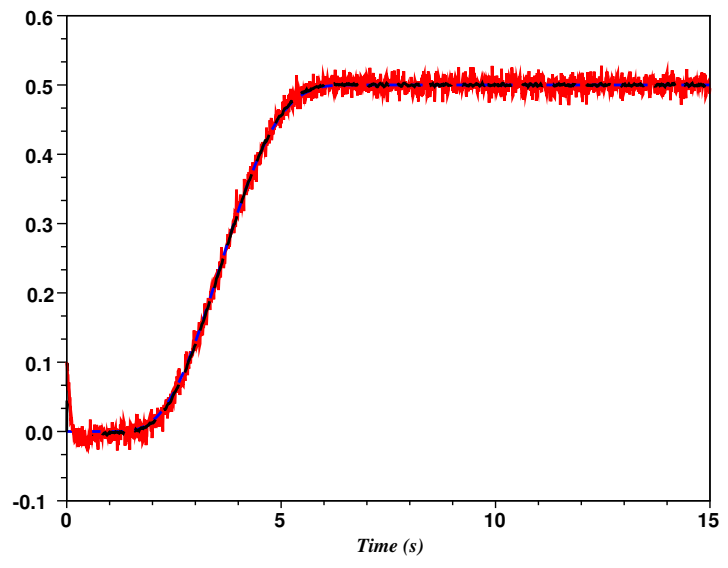

(b) Output (-) and denoised output (--)

Fig. 2: PI case

[15] M. Mboup, C. Join, M. Fliess, Numerical differentiation with annihiators in noisy environment, Numer. Algor., vol. 50, pp. 439-467, 2009.
[16] A. O'Dwyer, Handbook of PI and PID Controller Tuning Rules $\left(2^{\text {nd }}\right.$ ed.), Imperial College Press, 2006. 


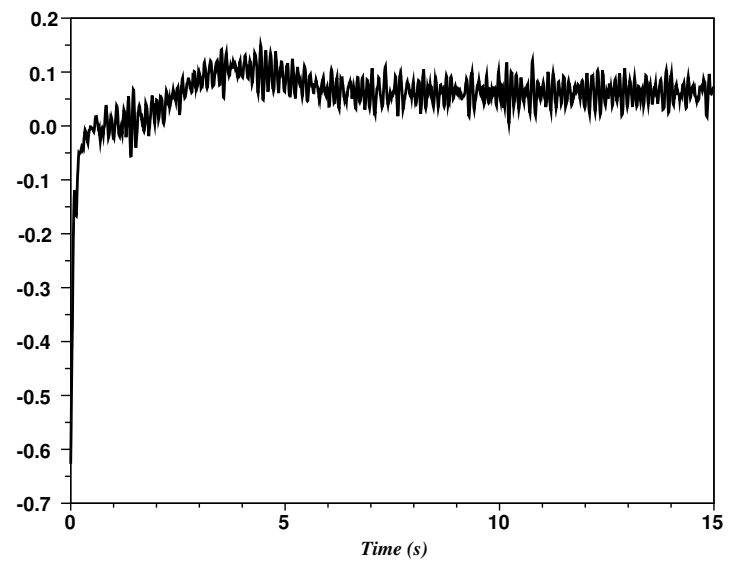

(a) Input

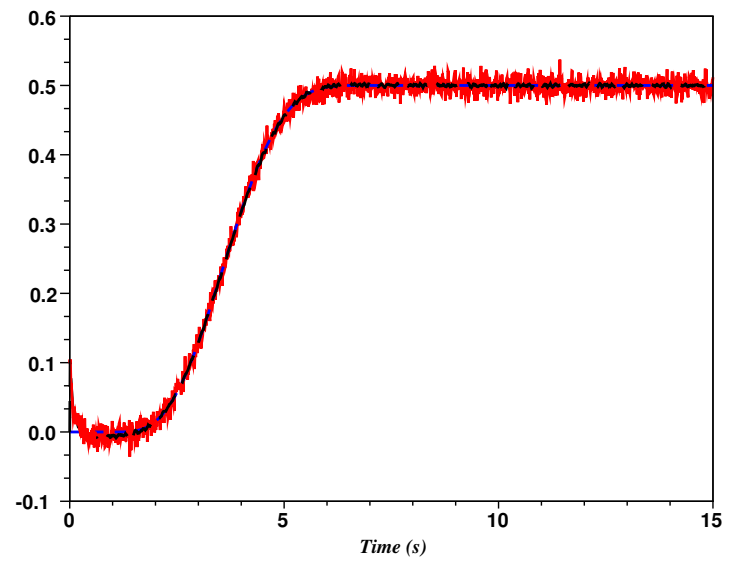

(b) Output (-) and denoised output (- -)

Fig. 3: i-PI case

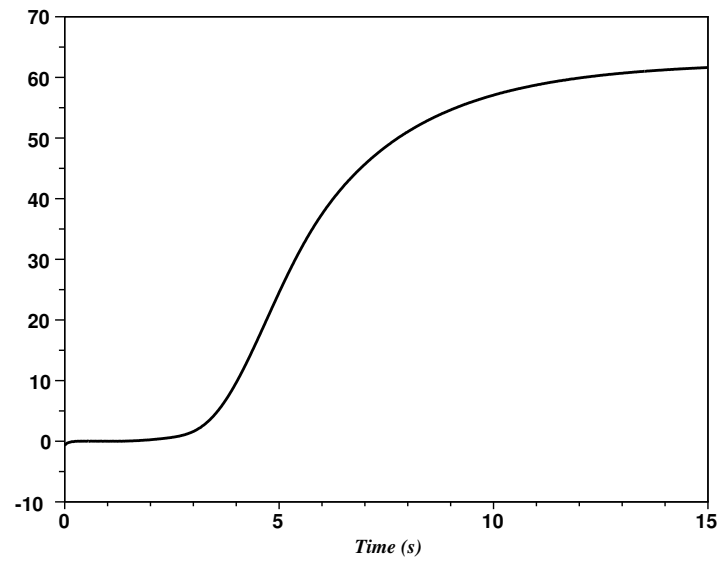

(a) Input

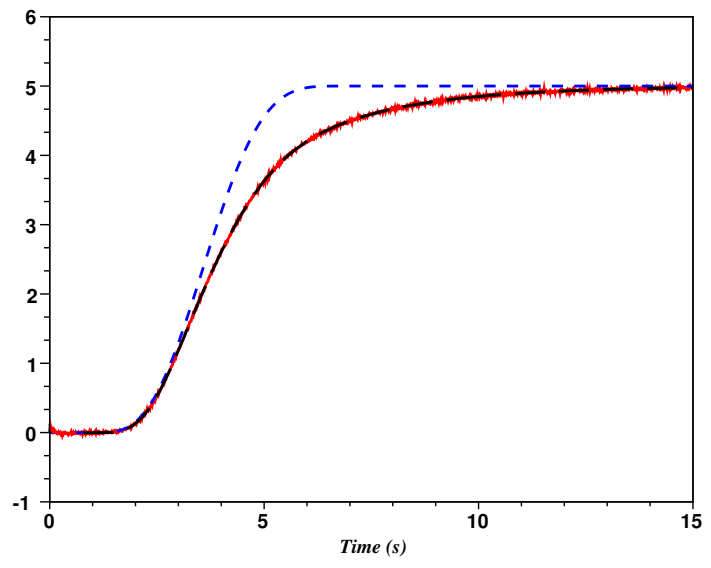

(b) Output (-) and denoised output (- -)

Fig. 4: PI in case of large amplitude setpoint change

[17] S. Riachy, M. Fliess, C. Join, J.-P. Barbot, Vers une simplification de la commande non linéaire : l'exemple d'un avion à décollage vertical, $\sigma^{e}$ Conf. Internat. Francoph. Automatique, Nancy, 2010 (online http://hal.inria.fr/inria-00463605/en/).

[18] J. Villagra, B. d'Andréa-Novel, S. Choi, M. Fliess, H. Mounier, Robust stop-and-go control strategy: an algebraic approach for non-linear estimation and control, Int. J. Vehicle Autonomous Systems, vol. 7, pp. 270-291, 2009

(online http://hal.inria.fr/inria-00419445/en/). 


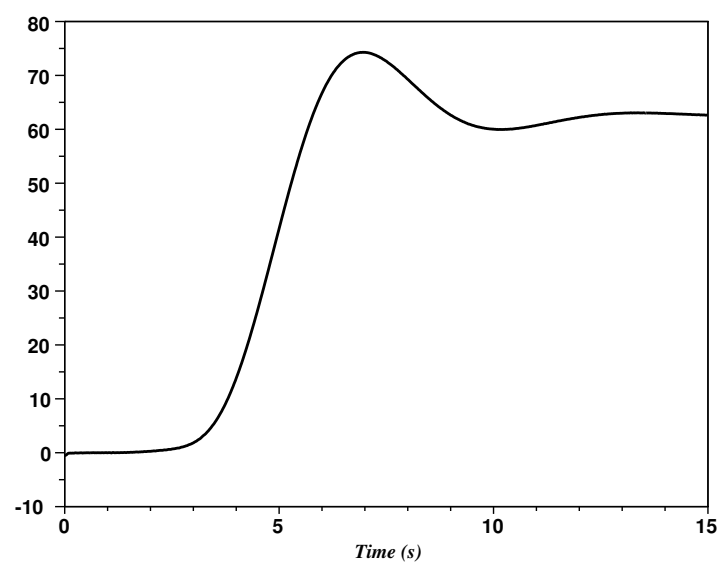

(a) Input

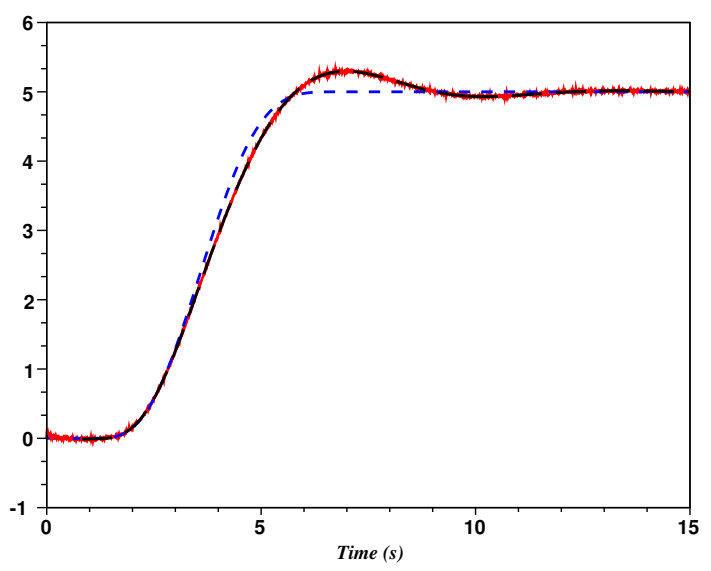

(b) Output (-) and denoised output (- -)

Fig. 5: i-PI in case of large amplitude setpoint change

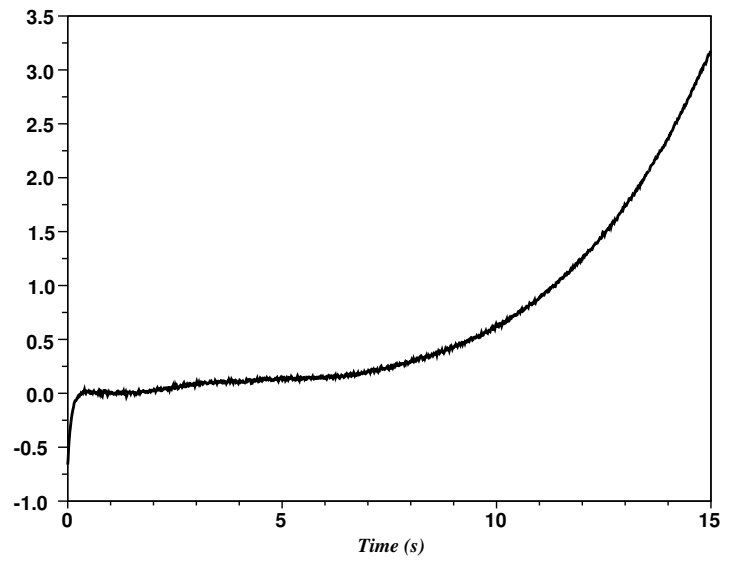

(a) Input

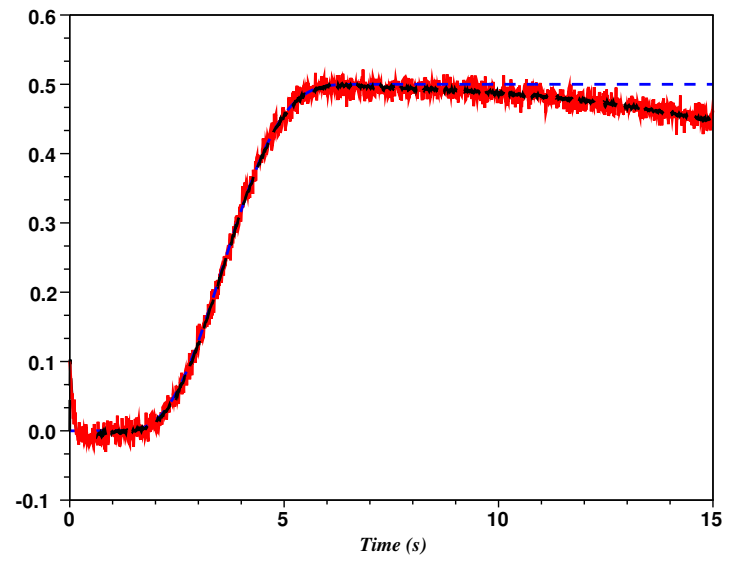

(b) Output (-) and denoised output (- -)

Fig. 6: PI in case of power loss 


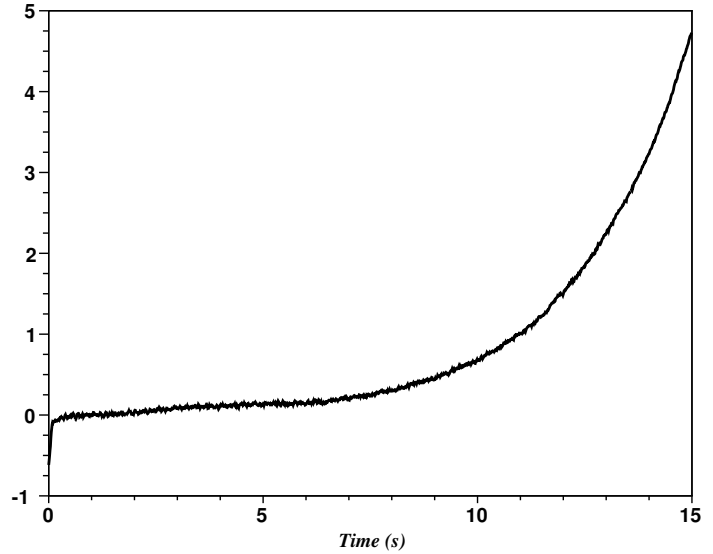

(a) Input

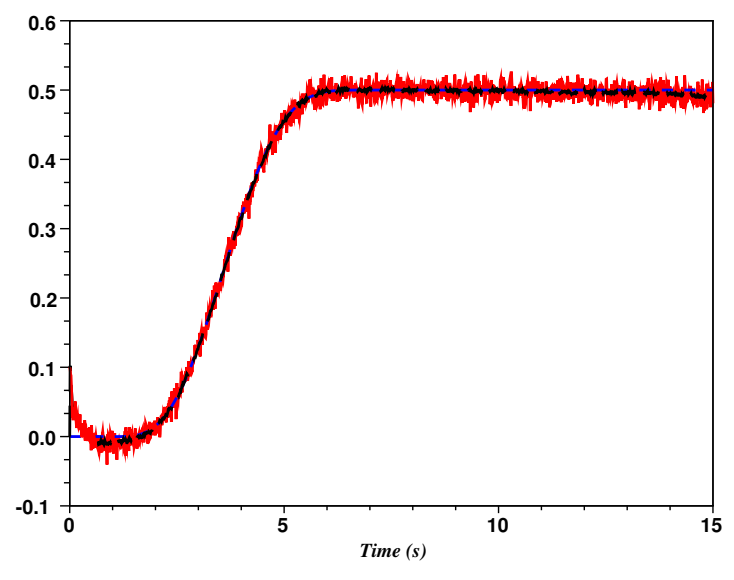

(b) Output (-) and denoised output (- -)

Fig. 7: i-PI in case of power loss 